\title{
Nursery rhymes e a correspondência formal e funcional na tradução de poesia infantil
}

Nilce M. Pereira

\begin{abstract}
Resumo: Este trabalho concentra-se na tradução de poemas infantis em língua inglesa, examinando, em particular, as denominadas nursery rhymes, componentes do cancioneiro popular na cultura do Reino Unido. Serão considerados aspectos formais e históricos dessa categoria poética e apresentadas sugestões de tradução para alguns poemas, com base nos conceitos de correspondência formal e correspondência funcional, elaborados por Paulo Henriques Britto, como aplicados ao processo tradutório (ademais de seu emprego na crítica de tradução poética). Foram selecionados para tradução e exemplificação das discussões três poemas de temáticas diversas, extraídos das coletâneas organizadas por Peter e Iona Opie, The Oxford Dictionary of Nursery Rhymes (1952/1997) e A Family Book of Nursery Rhymes (1964).

Palavras-chave: nursery rhyme, tradução, correspondência formal, correspondência funcional.
\end{abstract}

\section{A tradição britânica das nursery rhymes}

A tradição das nursery rhymes no Reino Unido remonta à Idade Média, considerando os relatos de Iona e Peter Opie (1997) sobre a identificação de trechos de poemas infantis em baladas do século XVI, nas descrições da infância de personalidades como Agrícola e Meister Altswert, em épocas anteriores, e até mesmo nos escritos de Bede (OPIE; OPIE, 1997 , p. 3, 6). No entanto, os autores apontam o início do século XVII como o período a partir do qual a presença dessa categoria poética é mais 
fortemente demarcada na cultura britânica, e que deve, assim, datá-la (OPIE; OPIE, 1997, p. 6); e os séculos posteriores, em que os poemas passaram a figurar livros e coleções dedicadas ao gênero. Destacam-se, entre as publicações do século XIX, Songs for the Nursery (1805), The Popular Rhymes of Scotland (1824 e 1842) e as coletâneas do historiador James Orchard Halliwell, The Nursery Rhymes of England (1842) e Popular Rhymes and Nursery Tales (1849), entre outras.

A propósito do termo - e razão de sua utilização como empréstimo, neste trabalho -, acredita-se que as nursery rhymes ficaram assim conhecidas, a partir do início do século XIX, por influência de publicações como Rhymes for the Nursery (1806), das irmãs Ann e Jane Taylor, e Nursery Rhymes for the Amusement of Children (1812), organizada por James Kendrew de York, ambas de imenso sucesso entre os ingleses (OPIE, 1996, p. 177). Anteriormente a esse período, termos como "cantigas", "canções", "cançonetas" e "modinhas", além de "Tommy Thumb's songs" e "Mother Goose's" (figurantes de outros títulos), eram comumente utilizados; e, ao final, "Mother Goose's", "Mother Goose's rhymes" ou "Mother Goose's songs" passaram a ser a designação norte-americana desses tipos de poemas (OPIE, 1996, p. 177), nomes por que também são mais conhecidos no Brasil, com as denominadas "Mamãe Gansa" ou "Contos da Mamãe Gansa"1.

De fato, a separação dessas nomenclaturas não é tão simples e sua observação histórica revela algumas controvérsias. É conhecida, por exemplo, a história de um senhor de nome John Fleet Eliot, residente em Boston em meados do século XIX, que enviou uma carta ao jornal Boston Transcript, alegando que um volume de poemas infantis lançado nos Estados Unidos em 1719, supostamente de autoria original, teria recebido o título de Mother Goose's Melody - o que antecederia as publicações inglesas Mother Goose's Tales (1768) e Mother Goose's Melody (1780?) e as americanas, Mother Goose's Melody (1885), Mother Goose's Quarto (1825) e Mother Goose's Melodies (1833) - e que a própria "Mother Goose" teria sido uma

\footnotetext{
Embora, no Brasil, esses títulos refiram-se mais precisamente ao clássico Histoires, ou contes du temps passé, avec des Moralitez (Claude Barbin, 1697), atribuído a Perrault. cuja inscrição na ilustração de frontispício da primeira edição, "Contes de ma mère l'Oye", tornou-se a designação por meio da qual o livro ficou conhecido (CARPENTER; PRICHARD, 1984, p. 402) e deu origem à tradução em português. Exemplos incluem Contos da Mamãe Gansa, de Perrault (Paraula, 1994), com tradução de Ayalla Kluwe de Aguiar, entre outras tradutoras, e ilustrações de Doré, e Mamãe Gansa (Cia. das Letrinhas, 1997), traduzido por José Paulo Paes, com ilustrações de Scott Cook.
} 
senhora americana (cf. CARPENTER; PRICHARD, 1984, p. 362). Ao passo que essa teoria demonstra instigante e até mesmo recorrente em obras de referência sobre a literatura infantil, de acordo com os Opie (1997, p. 37-38), as evidências (ou a falta delas) atestam as inconsistências na história de Eliot, uma vez que, primeiramente, ele atribuiu o seu conhecimento da existência do suposto livro à informação que lhe fora dada por um terceiro, um certo senhor Crowninshield, que teria visto o livro na biblioteca da Sociedade Americana de Antiquários, mas que estava morto na época em que Eliot fez a denúncia. Depois, pela própria inexistência do volume na referida biblioteca (CARPENTER; PRICHARD, 1984, p. 362). Essas questões, no entanto, não pertencem ao escopo deste trabalho, sendo que a utilização de nursery rhymes deve-se, portanto, ao fato de concentrar-se nos poemas pela perspectiva da tradição britânica e considerando, grosso modo, a diferenciação de ambas as designações.

As nursery rhymes incluem várias categorias de versos e um sem número de temas, apropriados a todos os tipos de ocasião, no que diz respeito à criança, especialmente em idade pré-escolar. Contam-se entre as formas poéticas mais comuns as canções de ninar:

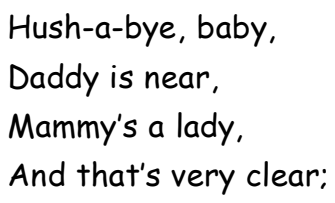

os riddles, poemas que trazem um enigma a ser decifrado, conhecidos das crianças brasileiras como o que é, o que é?:

As round as an apple,

As deep as a cup,

And all the king's horses

Cannot pull it up:

as counting-out rhymes, do tipo "eenie, meenie, minie, mo", utilizadas para selecionar ou excluir um participante em uma brincadeira, por exemplo, e que também encontram correspondentes na cultura brasileira com "uniduni-têe, salamê-minguê"; e os infant amusements, que envolvem as rimas acompanhadas de ações específicas (e que, novamente, encontra a sua versão no Brasil, por exemplo, com "eu com todas, eu com ela, eu sem ela...", em que se batem as palmas das mãos à medida que se recita): 
Clap hands, clap hands,

Till father comes home;

For father's got money,

But mother's got none.
Ring a ring a rosie,

A bottle full of posie,

All the girls in our town,

Ring for little Josie.

A variedade dos temas, por sua vez, inclui desde o abecedário e os números, passando pelos acontecimentos do cotidiano, os animais de estimação e as brincadeiras infantis, até aqueles que envolvem uma moral; $e$ não excluindo, como os Opie $(1997$, p. 2) observam, as "extravagâncias", os "convites à irresponsabilidade" e as "ilustrações de violência":

Mary, Mary, quite contrary,

How does your garden grow?

With silver bells and cockle shells,

And pretty maids all in a row.

Mother and Father and Uncle Dick

Went to London on a stick

The stick broke and made a smoke,

And stifled all the London folk.

A man of words and not of deeds

Is like a garden full of weeds ${ }^{2}$.

A origem das nursery rhymes encontra-se particularmente na literatura adulta. Opie e Opie (1997, p. 18-28) relacionam as baladas impressas, as partituras musicais, as produções teatrais, as canções folclóricas, as pantomimas e as sátiras políticas como as principais fontes das nursery rhymes, que foram incorporadas ao universo infantil e preservadas ali; $e$ que também explicam o costume de se cantar os poemas. De acordo com

2 Os exemplos do parágrafo foram extraídos das coletâneas e trabalhos organizados pelos Opie, sendo "Hush-a-bye, baby" - as nursery rhymes são geralmente identificadas pelo primeiro verso -, "As round as an apple", "Clap hands, clap hands", "Ring a ring a rosie", "Mary, Mary..." e "A man of words..." pertencentes ao Oxford Dictionary of Nursery Rhymes (1952), respectivamente nas páginas 61, 55/56, 196, 364, 301, 3013 286; e "Mother and Father...", inclusa em A Family Book of Nursery Rhymes (1964, p. 54). A resposta do riddle "As round as an apple" é: "um poço". 
Cecily Rayson Hancock (1997), não apenas uma grande parte das nursery rhymes são ou foram canções, ou fragmentos de canções, como uma outra grande parte daquelas escritas como poemas adquiriram melodias posteriormente (HANCOCK apud OPIE; OPIE, 1997, p. 44). Títulos como The Baby's Bouquet (1877) e The Baby's Opera (1879) de Walter Crane ${ }^{3}$ e The Oxford Nursery Song Book (1933), de Sir Percy Buck, exemplificam coletâneas cujos poemas são todos acompanhados por melodias. $E$, em SingSong: A Nursery Rhyme Book (1922), de Christina Rossetti, as nursery rhymes foram, igualmente, idealizadas para serem entoadas como modinhas.

Por fazerem parte do legado oral e caracterizarem a autoria anônima na maioria dos casos, as nursery rhymes sofreram modificações em sua transmissão de uma geração a outra. Alguns poemas podem ser encontrados em várias versões, o que se aplica tanto aos versos, em si, quanto à melodia que os acompanha (HANCOCK apud OPIE; OPIE, 1997, p. 45-46). Um outro aspecto dessas composições é que encontram correspondentes em praticamente todas as culturas européias, algumas podendo remontar até mesmo a variações primitivas das línguas faladas nas regiões que as envolvem (OPIE; OPIE, 1997, p. 9-13). E chama a atenção a respeito das nursery rhymes sobretudo a sua capacidade de perpetuação ao longo de vários séculos, em grande parte em decorrência das inúmeras referências que se fazem a elas, principalmente na música e na literatura de diferentes períodos, seja por meio de paródias, criações intertextuais ou, mesmo, de sua reprodução literal.

Na música, para citar uns poucos exemplos, Buddy Guy (em $A$ Man and the Blues, Vanguard, 1968) e Paul McCartney \& The Wings (no compacto de 1972, pela Apple), deram roupagens musicais distintas a "Mary Had a Little Lamb", e a versão, em blues, de Guy foi regravada por Steve Ray Vaughan em seu álbum de estréia, Texas Flood, de 1983. "A-tisket, atasket"4 ficou famosa na voz de Ella Fitzgerald, no sucesso de mesmo nome, com arranjos de Van Alexander, gravado com a banda de Chick Webb (Decca Records, 1938). Ella Fitzgerald também fez alusão a "Little boy

3 Na capa de The Baby's Opera (uma referência a The Beggar's Opera, de Gay) consta apenas o nome de Walter Crane, que, de fato, é o autor das ilustrações para o volume. A autoria das melodias deve ser creditada a sua irmã, Lucy Crane, a quem Walter Crane menciona no Dictionary of National Biography (HANCOCK apud OPIE; OPIE 1997, p. 44).

4 Embora considerada uma nursery rhyme primeiramente identificada nos Estados Unidos (veja: Wikipedia em inglês). 
blue, come blow your horn" em "Big Boy Blue", composta por Jack Lawrence, Dan Howell e Peter Tinturin (ASCAP, 1937). E Marillion reproduziu "Lavenders blue, dilly dilly, lavenders green" no refrão de "Lavender" (Misplaced Childhood, EMI, 1985).

$\mathrm{Na}$ literatura, por sua vez, podem-se mencionar "The House that Jack Built", cuja forma narrativa cumulativa foi utilizada por Mark Twain, em Mark Twain's (Burlesque) Autobiography and First Romance (1871), como sátira política por meio de ilustrações ${ }^{5}$; as sessenta e oito nursery rhymes encontradas em Finnegans Wake e relacionadas por Mabel P. Worthington (1957); e os poemas de Adventures of Alice in Wonderland (1865) e Through the Looking-Glass and What Alice Found There (1871). Personagens como Humpty Dumpty, do poema "Humpty Dumpty sat on a wall" - e razão por que aparece sentado em um muro enquanto conversa com Alice-, ou paródias como "Twinkle Twinkle little bat", do clássico "Twinkle, twinkle, little star", das irmãs Taylor, a que Carroll faz referência, eram identificáveis a seus leitores por constituírem-se nursery rhymes conhecidas (cf. notas de Martin Gardner em CARROLL, 1965). Esses exemplos servem para comprovar o apelo, popularidade e trânsito das nursery rhymes em todos os universos da cultura de língua inglesa.

\section{A tradução de nursery rhymes}

No que diz respeito à tradução, as nursery rhymes certamente constituem desafios, estando sujeitas a decisões concernentes a forma e estilo, características da tradução de poesia. Ou seja, se aplicados conceitos tradutórios como os de James Holmes, por exemplo, à tradução de nursery rhymes, com relação à forma, o tradutor poderá escolher entre a abordagem mimética, na qual a forma do original é replicada na tradução, a analógica, em que uma forma pertencente à cultura alvo é utilizada com o intuito de promover uma função cultural semelhante, ou a orgânica, em

5 Mark Twain's (Burlesque) Autobiography and First Romance é um livreto composto de três obras, "A Burlesque Autobiography", "An Awful-Terrible Medieval Romance" (primeiramente publicado no Express, de Buffalo), e a referida "The House That Jack Built". Twain reproduz o poema, com algumas alterações, colocando, em páginas separadas, cada verso como legenda para as figuras de políticos da época (ilustrados a seu pedido), por sua vez, representando os animais ou inseridos nos contextos mencionados no poema: "This is the malt that lay in the house that Jack built", "This is the rat that ate the malt...", "This is the cat that caught the rat...", e assim por diante (cf. DAVID, 1986, p. 69-106). 
que a forma do original é abandonada, em detrimento de outra, que melhor se adapte ao que o tradutor tenha em mente (HOLMES, 1988, p. 25-28 apud JONES, 2011, p. 173); e manter-se "fiel" (minhas aspas) ao estilo, uma vez que esse elemento representa "a atitude do autor com relação ao conteúdo" (BOASE-BIER, 2004, p. 29-29 apud JONES, 2011, p. 173). Tais prerrogativas podem levar o tradutor a criar, como Phillips (2001, p. 2324) descreve, "um poema, na língua alvo, a ser lido e apreciado por seu próprio mérito e como texto literário independente ${ }^{6 \prime \prime}$ (apud JONES, 2011, p. 172).

É também o caso que, na condição de poemas musicados, as nursery rhymes podem ser motivo de aplicação de teorias para a tradução de canções, que relacionam a produção verbal a uma aderência necessária aos padrões da música. Por exemplo, ao considerar a tradução de ópera, Ronnie Apter (1985, p. 309) salienta a tarefa mais importante do tradutor, de "colocar o significado correto na nota correta" (apud BOSSEAUX, 2011, p. 186); e Peter Low (2005, p. 185), inclui a "naturalidade" [de expressão] e a "possibilidade de ser cantado" (além de elementos mais óbvios como o ritmo) entre os critérios para a tradução de música popular (apud BOSSEAUX, 2011, p. 188).

No contexto da literatura traduzida no Brasil, Ana Maria Machado deu atenção ao aspecto musical das nursery rhymes em sua tradução dos poemas em Alice no País das Maravilhas (CARROLL, 1997). A tradutora fez com que cada canção infantil parodiada no original - os poemas de Alice são paródias das verdadeiras nursery rhymes (cf. CARROLL, 1965) - se ajustasse a uma melodia conhecida na cultura brasileira, fosse como canção infantil, folclórica ou de compositores populares, transformando o poema traduzido, da mesma forma, em uma paródia, como expresso nos poemas abaixo, extraídos, respectivamente, de Carroll (1965, p. 38) e Carroll (1997, p. 25):

6 [a poem in the target language which is readable and enjoyable in its own right, with merit as an independent, literary text]

[place the right meaning on the right note] 


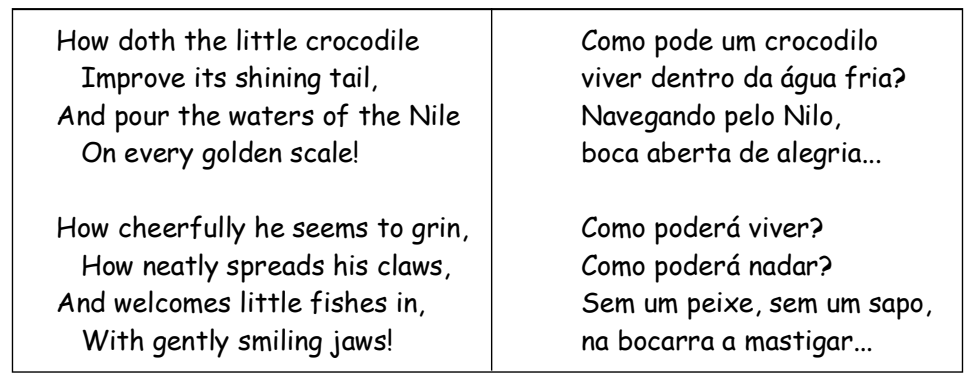

Machado explica a utilização desse recurso como tentativa de "transmitir a intimidade absoluta com os jogos de linguagem que caracteriza Carroll", "[r]espeitar o papel que essa brincadeira desempenha na invenção da história", e "[f]azer com que todos os poemas-paródia no texto fossem fáceis de identificar (como eram para o leitor britânico de seu tempo)" (CARROLL, 1997, p. 133). Esses intuitos são oportunos para a menção do pensamento de Paulo Henriques Britto sobre a avaliação de tradução poética, da maneira como podem ser aplicáveis à tradução de nursery rhymes, e de como os elementos formais, estilísticos e a musicalidade podem ser equilibrados no ato tradutório.

A teoria de Britto (apresentada em comunicação pessoal, em 12 de maio de $2011^{8}$ ) foi originalmente elaborada para fornecer os meios para uma avaliação mais consistente da tradução poética, tida, de modo geral, como fundamentada em princípios subjetivos como a capacidade ou incapacidade do tradutor de "captar a essência do original" ou seu trabalho como meio de "incorporar" o poeta traduzido. Contrariamente a essa tendência, o autor propõe critérios de análise que levem a uma visão concreta do material avaliado, bem como promovam o entendimento e localização das transformações do processo tradutório; e que se possam demonstrar eficazes em medir a relação do poema original e traduzido em termos de graus de correspondência. A partir dos conceitos de correspondência formal e correspondência funcional, como os estabelece, Britto acrescenta à análise de poesia traduzida a possibilidade de verificar até que ponto os elementos formais do original (tipo de verso, número de sílabas, colocação de acentos, etc.) são reproduzidos na tradução, e quais elementos são manipulados (por meio de acréscimos, omissões, uso de arcaísmos, etc.), para que uma estrutura correspondente seja recriada (seja no nível formal ou semântico).

8 Cf. http://www.youtube.com/watch?v=BC8mrLouP1I 
A atenção a esses critérios é importante porque, como Britto afirma, certos níveis de correspondência formal são impossíveis de serem alcançados. Por exemplo, a recriação de um verso composto, em inglês, na forma do pentâmetro jâmbico (com padrão de acentuação 2-4-6-8-10), dificilmente - tampouco poderia ser uma exigência - os acentos recairiam nas mesmas sílabas no verso traduzido em português, o que, necessariamente, demandaria uma outra forma na última língua (BRITTO, 2011, comunicação pessoal). Igualmente, os elementos de um poema carregam pesos distintos. A rigidez formal, por exemplo, pode ser denotadora de aspectos significativos em um poema, ao passo que, em outro, a escolha do vocabulário é que exerça o papel mais importante na significação. É necessário, assim, que o tradutor não apenas esteja ciente de quais sejam, o que Britto denomina, os "elementos estruturais" e os "elementos acidentais" do poema original, como, da mesma forma, faça distinção entre eles no seu poema, priorizando o que seja essencial (BRITTO, 2011, comunicação pessoal).

Um direcionamento nesse sentido (embora não abordando especificamente a tradução) é demonstrado por Iona Opie (1996, p. 177), em sua consideração da melodia como um dos elementos estruturais das nursery rhymes, em relação ao conteúdo significativo:

A melodia é mais importante do que as palavras, pois, se a melodia for branda, a criança não terá condições de saber se está sendo subornada para ficar quieta ("Dinna [...]/Vai ganhar um bolo/Quando o boleiro chegar") ou ameaçada ("Nenê, nenê, nenê travesso/Fique quieto, seu chorão"); e tampouco poderá ficar com medo do conteúdo dos versos da canção de ninar mais conhecida, que diz, "Dorme, nenê, na copa de uma árvore/Quando o vento soprar o berço vai balançar/Quando o galho quebrar o berço vai despencar/e o nenê, se espatifar com berço e tudo?.

$E$, do mesmo modo, Britto propõe que, em face da antiguidade das nursery rhymes, a especificidade de suas denotações (a Torre de Londres, a rainha, as batalhas inglesas), e, em muitos casos, a sintaxe perten-

9 [The tune is more important than the words, for if the tune is soothing, the infant cannot know whether it is being bribed into quietness (Dinna mak' a din, / An' ye'll get a cakie/When the baker comes in) or threatened (Baby, baby, naughty baby/ Hush you squalling thing, I say). Nor can it be frightened by the story line of the best known of all lullabies, Hush-a-bye, baby, on the tree top,/When the wind blows the cradle will rock,/When the bough breaks the cradle will fall,/Down will come baby, cradle and all] 
cente a fases evolutivas distintas da língua inglesa, a organização semântica é pouco representativa na tradução desse gênero (BRITTO, 2011, comunicação pessoal).

Entendendo que as afirmações dos dois autores, embora coincidentes com relação à valorização dos elementos da construção formal, em detrimento das significações, enfatizem principalmente a identificação dos aspectos chave das nursery rhymes, e pensando especialmente na aplicabilidade dos conceitos de correspondência formal e funcional (também) ao processo tradutório desse gênero poético, este trabalho propõe, por fim, a tradução de alguns poemas entre aqueles reunidos pelos Opie, nas coleções de 1952/1997 e 1964, como apresentado a seguir. Sugerese, como estabelecido na metodologia de Britto, a escansão dos poemas originais e traduzidos para a definição de suas respectivas estruturas e comparação entre cada par original-tradução para a verificação de seus paralelismos e/ou discrepâncias e, assim, (se possibilitados) seus tipos e graus de correspondência; $e$, ainda, a utilização dos princípios de correspondência formal e funcional como exercícios tradutórios na busca de soluções apropriadas a cada caso.

\section{Algumas (tentativas de) possibilidades}

$O$ primeiro poema selecionado encontra-se em $A$ Family Book of Nursery Rhymes (1964, p. 163) e possui uma única estrofe:

$$
\begin{aligned}
& \text { Fishie, fishie, in the brook } \\
& \text { Daddy catch him with a hook, } \\
& \text { Mamma fry him in a pan, } \\
& \text { Baby eat him like a man. }
\end{aligned}
$$

Ele faz parte de uma série de poemas sobre peixes e pescaria, cuja melodia pode ser encontrada na interne $t^{10}$. Uma escansão simplificada dos quatro versos revela as seguintes características formais:

10 Cf. $h+t p: / / w w w . y o u t u b e . c o m / w a t c h ? v=t n j O c N R E D c 4$ 


\begin{tabular}{|l|c|c|c|c|c|c|}
\hline \multicolumn{1}{|c|}{ Poema original } & RITMO & S & A & ER & R & ALIT \\
\hline Fishie, fishie, in the brook & $/-/-1-/$ & 7 & 4 & $1-3-5-7$ & a & $/ f /$ \\
Daddy catch him with a hook, & $/-/-1-/$ & 7 & 4 & $1-3-5-7$ & a & \\
Mamma fry him in a pan, & $/-/-1-/$ & 7 & 4 & $1-3-5-7$ & b & \\
Baby eat him like a man. & $/-/-1-/$ & 7 & 4 & $1-3-5-7$ & b & \\
\hline
\end{tabular}

$\mathbf{S}=$ no. de sílabas; $\boldsymbol{A}=$ no. de acentos; $E R=$ esquema rítmico; $\mathbf{R}=$ rimas; $\mathbf{A L I T}=$ aliterações

"Fishie, fishie, in the brook" é uma nursery rhyme tradicional, uma quadrinha, como é denominada, utilizando-se o conceito de quatro linhas ou dois pares de couplets (disticos) que contam uma história completa. Esses "pares de versos" geralmente rimam entre si, de modo que o padrão de rimas do poema é típico: aabb. É também característica das nursery rhymes a divisão silábica em sete sílabas. No poema em questão elas formam o padrão trocaico, com acentos na primeira, terceira e sétima sílabas e um acento secundário na quinta sílaba. O contrato métrico forma, assim, o denominado long meter (cf. ballad meter: PREMINGER; BROGAN, 1993, 118-120), de quatro acentos em cada linha (referenciado 4-4-4-4), sendo que o penúltimo acento, secundário, é sempre contado. Uma aliteração em / $f$ / (nas sílabas tônicas de "fishie") marcam o primeiro verso.

Considerou-se que, nesse poema, tanto o ritmo, que constitui a base da nursery rhyme enquanto canção popular, bem como a distinção semântica do último verso, em que um bebê que "come como um homem" constitui o elemento surpresa no fechamento da história que está sendo descrita (podendo, por sua vez, levar a conotações hiperbólicas de voracidade e grandes quantidades de comida, além do aspecto de estranheza), deveriam fundamentar a tradução. Para que, ao mesmo tempo, pudesse haver a visualização de como, a princípio, se sugere a aplicação dos conceitos de correspondência formal e funcional ao processo tradutório, a tradução foi realizada em três etapas, resultando em três versões do mesmo poema. A primeira delas, acompanhada de seu quadro estrutural, vem como segue:

Peixinho, peixinho, que beija e belisca,

Papai o fisgou com anzol e com isca,

Mamãe fez bem frito, "que bela tainha",

Neném comeu tudo, "que boa papinha". 


\begin{tabular}{|l|c|c|c|c|c|}
\hline \multicolumn{1}{|c|}{ Poema traduzido 1 } & RITMO & S & A & R & ALIT \\
\hline Peixinho, peixinho, que beija e belisca, & $-/--/-1 /-/$ & 11 & 4 & a & $/ x /$, \\
Papai o fisgou com anzol e com isca, & $-/--/--/-1 /$ & 11 & 4 & a & $/ \mathrm{b} /$, \\
Mamãe fez bem frito, "que bela tainha", & $-/--/-1 /-/$ & 11 & 4 & $\mathrm{~b}$ & $/ \mathrm{f} /$, \\
Neném comeu tudo, "que boa papinha". & $-/--/--/--/$ & 11 & 4 & $\mathrm{~b}$ & \\
\hline
\end{tabular}

Esse poema tem no verso de onze sílabas (endecassílabo), com esquema (rítmico) de acentuação na segunda, quinta, oitava e décima primeira sílabas, o principal elemento de correspondência da musicalidade do poema original. Os versos formam o padrão do long meter, como definido acima, caracterizado pelos quatro acentos em cada verso, resultando no contrato métrico 4-4-4-4. As rimas aabb mantêm o padrão original; e as aliterações em /+"/, ("peixinho", "peixinho") e em /b/ ("beija", "belisca") e /f/ ("fez", "frito"), embora ocorrendo em sílabas átonas, no caso das últimas, contribuem para os efeitos de sonoridade, também demarcados pela oposição entre /s/ ("isca", "belisca") e / z/ ("fisgou", "anzol"), entre outras. Essa estrutura foi originada a partir do paralelismo na tradução de "fishie, fishie" com "peixinho, peixinho", que, por conseguinte, promoveu a extensão do verso. No entanto, o poema não cumpre o fechamento surpreendente do último verso, não correspondendo formal ou funcionalmente ao poema original, e tornando inválido o princípio de paralelismo a partir do termo "fishie". Desse modo, duas outras versões foram elaboradas, que pudessem atender aos requisitos básicos apontados. Elas vêm a seguir, novamente acompanhadas de seus respectivos quadros estruturais:

Peixinho novo do ribeirinho,

Papai pescou no seu barquinho,

Mamãe fritou na frigideira,

Neném comeu de mamadeira.

\begin{tabular}{|l|l|l|l|l|l|c|}
\hline \multicolumn{1}{|c|}{ Poema traduzido 2 } & RITMO & S & A & ER & R & ALIT \\
\hline Peixinho novo do ribeirinho, & $-/-1--1$ & 9 & 3 & $2-4-9$ & $\mathrm{a}$ & $/ \mathrm{p} /$, \\
Papai pescou no seu barquinho, & $-1-1--1$ & 8 & 3 & $2-4-8$ & $\mathrm{a}$ & $/ \mathrm{m} /$, \\
Mamãe fritou na frigideira, & $-1-1--1$ & 8 & 3 & $2-4-8$ & $\mathrm{~b}$ & $/ \mathrm{f} /$, \\
Neném comeu de mamadeira. & $-1-/--1$ & 8 & 3 & $2-4-8$ & $\mathrm{~b}$ & $/ \mathrm{n} /$ \\
\hline
\end{tabular}


Peixinho bom do ribeirão,

Papai pescou com um arpão,

Mamãe fritou para o jantar.

Neném comeu sem mastigar.

\begin{tabular}{|l|c|c|c|c|c|c|}
\hline \multicolumn{1}{|c|}{ Poema traduzido 3 } & RITMO & S & A & ER & R & ALIT \\
\hline Peixinho bom do ribeirão, & $-/-/-1-/$ & 8 & 4 & $2-4-6-8$ & $\mathrm{a}$ & $/ \mathrm{p} /$ \\
Papai pescou com um arpão, & $-/-/-1-/$ & 8 & 4 & $2-4-6-8$ & $\mathrm{a}$ & $/ \mathrm{b} /$ \\
Mamãe fritou para o jantar, & $-/-/-1-/$ & 8 & 4 & $2-4-6-8$ & $\mathrm{~b}$ & $/ \mathrm{m} /$ \\
Neném comeu sem mastigar. & $-/-/-1-/$ & 8 & 4 & $2-4-6-8$ & $\mathrm{~b}$ & $/ \mathrm{h} /$ \\
\hline
\end{tabular}

Nessas versões, exceto na primeira linha do primeiro poema, o tamanho do verso é reduzido para oito sílabas (octossílabo), o mesmo número de sílabas do original. Na primeira versão (poema traduzido 2) os versos possuem três acentos, que recaem, em sua maioria, na segunda, quarta e oitava sílabas; e, na segunda versão (poema traduzido 3), são quatro os acentos por linha, recaindo na segunda, quarta, sexta e oitava sílabas em cada uma. As rimas formam o esquema aabb em ambas as traduções, diferenciadas apenas pelas classificações entre rimas pobres em aa ([ribeirinho/barquinho] e [ribeirão/arpão]), em que as palavras pertencem à mesma classe gramatical; e rimas ricas em bb ([frigideira/mamadeira], cuja identificação se dá desde o fonema /d/ anterior à vogal tônica; e [jantar/ mastigar], que pertencem a classes gramaticais distintas), nos dois poemas. Embora em nenhuma das versões haja a ocorrência de aliterações propriamente ditas, a repetição dos fonemas $/ \mathrm{p} /, / \mathrm{m} /, / \mathrm{f} /, / \mathrm{n} /$, na primeira versão, e /p/, /b/, /m/, /n/, na última, servem para conferir uma constância na sonoridades dos poemas, reforçando o aspecto melódico em cada uma. E há nos dois poemas, por fim, com relação ao último verso, uma correspondência com o original no plano do sentido: apesar de os significados serem diferentes em ambos, eles possuem a estranheza e o inesperado comuns ao verso original.

Essas conclusões podem ser delineadas mais explicitamente, considerando os quadros comparativos com as três traduções, como organizado abaixo:

\begin{tabular}{|l|l|}
\hline Quadro comparativo: poema traduzido 1 \\
\hline Fishie, fishie, [in the brook] & Peixinho, peixinho, que beija e belisca, \\
Daddy catch him with [a] hook, & Papai o fisgou com anzol e com isca, \\
Mamma fry [him] [in a pan], & Mamãe fez bem frito, "que bela tainha", \\
Baby eat [him] [like a man]. & Neném comeu tudo, "que boa papinha". \\
\hline $\begin{array}{l}\text { Paralelismos = negrito Supressões = colchetes } \quad \text { Acréscimos = sublinhado } \\
\text { Alterações semânticas = itálico }\end{array}$ \\
\hline
\end{tabular}




\begin{tabular}{|l|l|}
\hline Quadro comparativo: poema traduzido 2 \\
\hline Fishie, [fishie], in the brook & Peixinho novo do ribeirinho, \\
Daddy catch [him] [with a hook], & Papai pescou no seu barquinho, \\
Mamma fry [him] in a pan, & Mamãe fritou na frigideira, \\
Baby eat [him] [like a man]. & Nenê comeu de mamadeira. \\
\hline $\begin{array}{l}\text { Paralelismos = negrito Supréscimos = sublinhado } \\
\text { Alterações semânticas = itálico }\end{array}$ \\
\hline
\end{tabular}

\begin{tabular}{|c|c|}
\hline \multicolumn{2}{|c|}{ Quadro comparativo: poema traduzido 3} \\
\hline $\begin{array}{l}\text { Fishie, [fishie], in the brook } \\
\text { Daddy catch [him] with a hook, } \\
\text { Mamma fry [him] [in a pan], } \\
\text { Baby eat [him] [like a man]. }\end{array}$ & $\begin{array}{l}\text { Peixinho bom do ribeirão, } \\
\text { Papai pescou com um arpão, } \\
\text { Mamãe fritou para o jantar, } \\
\text { Nenêm comeu sem mastigar. }\end{array}$ \\
\hline Paralelismos $=$ negrito & Acréscimos = sublinhado \\
\hline
\end{tabular}

Observa-se que, na primeira tradução, o verso mais longo não apenas promoveu um nível muito baixo de correspondência formal, mas demandou um número maior de acréscimos, diminuindo, do mesmo modo, o nível de correspondência funcional, com relação ao poema original (uma vez que os significados se distanciaram e não produziram os efeitos correspondentes entre os dois). Na segunda e terceira traduções, contrariamente, a redução do tamanho do verso, favoreceu o aumento no nível de correspondência formal, mas, novamente, em função dos acréscimos, na segunda versão, um nível mais baixo de correspondência funcional foi obtido em comparação com a terceira versão. Com relação aos paralelismos e alterações semânticas, eles estão em equilíbrio nas três traduções. Os paralelismos foram caracterizados nos termos que formam a "espinha dorsal" do poema, os agentes ("fishie", "daddy", "mamma" e "baby") das ações descritas e, portanto, estruturando os três poemas. E as alterações semânticas, justificáveis em função da sintaxe do original, em que "catch", "fry" e "eat" estão no presente e não recebem a flexão da terceira pessoa; e pela versatilidade, principalmente de "catch" e "fry", para opções como "pegar", "pescar", "fisgar" (no caso de "catch"), e "fritar", "fazer frito", entre outras (no caso de "fry"), que facilitaram a construção dos versos. No último poema, no entanto, o mesmo número de acentos em cada verso e o mesmo padrão típico do mencionado long meter (4-4-4-4), o número maior de paralelismos e alterações, o número menor de acréscimos e a recriação do efeito do elemento surpreendente do último verso (considerado um elemento estrutural do original), tornam-no a versão que mais corresponde formal e funcionalmente ao original. 
A segunda nursery rhyme a exemplificar a aplicação dos conceitos de correspondência formal e funcional na tradução de poesia infantil encontra-se em uma outra coletânea organizada pelos Opie, A Family Book of Nursery Rhymes (1964). O poema escolhido, que consta na página 162, é o seguinte:

\author{
Rain, rain, go away, \\ This is mother's washing day; \\ Rain, rain, pour down, \\ Wash my mother's night-gown.
}

"Rain, rain..." compõe uma série de quadrinhas sobre a chuva, de que se tem notícia desde o final do século XVII, de acordo com os Opie; e que provavelmente pertence ao costume infantil de entoar canções para espantar a chuva, oriundo da antiguidade clássica (cf. OPIE; OPIE, 1952, p. 360-361). O quadro estrutural elaborado a partir de cada verso revela as seguintes características:

\begin{tabular}{|l|l|l|l|l|l|c|}
\hline \multicolumn{1}{|c|}{ "Rain, rain, go away" } & RITMO & S & A & ER & R & ALIT \\
\hline Rain, rain, go away & $/ / /-/$ & 5 & 4 & $1-2-3-5$ & A & $/$ / / \\
This is mother's washing day; & $/ / /-/ / /$ & 7 & 4 & $1-3-5-7$ & a & \\
Rain, rain, pour down, & $/ / / /$ & 4 & 4 & $1-2-3-4$ & b & \\
Wash my mother's night-gown. & $/ / /-/ /$ & 6 & 4 & $1-3-5-6$ & b & \\
\hline
\end{tabular}

O quadro revela novamente o long meter como característico do poema, uma vez que, apesar do número distinto de sílabas em cada verso (e, consequentemente o esquema rítmico variado), cada um possui quatro acentos, formando o contrato típico de acentuação 4-4-4-4 (cf. PREMINGER; BROGAN, 1993, p. 118-120). Uma única aliteração em /r/ caracteriza a estrofe. Porém, ela é mais demarcada pelos efeitos sonoros de repetição dos vocábulos "rain", na primeira e terceira linhas (coincidentes com as aliterações) e outros como "mother's" e "wash", que se repetem total ou parcialmente - no caso do último, somente o radical é repetido. E há, ainda, as assonâncias, ocasionadas pelo jogo entre vogais átonas e ditongos (tônicos) por todo o poema; e, principalmente, pelas rimas. Embora no último verso, o acento primário recaia sobre "night", visto que essa palavra é formada por dois substantivos, as rimas enfatizam os efeitos de sonoridade do poema. 
As rimas, de fato, foram consideradas embasadoras do poema, da mesma forma que a métrica. Tanto é assim que as várias versões encontradas pelos Opie para o segundo e quarto versos sempre asseguram a concretização das rimas aa: "Rain, rain, go away/Come again a Saturday/ Come again on April day/Come again midsummer day/Come again on washing day/Come on Martha's wedding day/Don't come back till Christmas day/ Little Arthur wants to play"; e bb: "Rain, rain, pour down/But not a drop on our town" (cf. OPIE; OPIE, 1952, p. 360-361). Desse modo, sugere-se para o poema uma tradução que privilegie as rimas, como na versão que se apresenta, seguida de seu quadro estrutural:

Chuva, chuva, vá embora;

Minha roupa está lá fora.

Chuva, chuva, caia agora:

Lave a minha camisola.

\begin{tabular}{|l|c|c|c|c|c|c|}
\hline Tradução de "Rain, rain, go away" & RITMO & S & A & ER & R & ALIT \\
\hline Chuva, chuva, vá embora; & $/-/-/-/-$ & 7 & 4 & $1-3-5-7$ & a & /?/ \\
Minha roupa está lá fora. & $/-/-/ / /-$ & 7 & 4 & $1-3-5-7$ & a & \\
Chuva, chuva, caia agora: & $/-/-/-/-$ & 7 & 4 & $1-3-5-7$ & a & \\
Lave a minha camisola. & $/-/--/ /-$ & 7 & 3 & $1-3-7$ & A & \\
\hline
\end{tabular}

De fato, em função do paralelismo entre "night-gown" e "camisola" (veja quadro abaixo), as rimas formam o esquema aaaA, distinto do original, visto que, nos dois últimos versos, somente a vogal [o] é repetida (rima imperfeita ou parcial). Entretanto, como a tradução também está embasada na métrica de quatro acentos (repare-se que o acento secundário não é contado no segundo verso), formando o padrão trocaico - sendo que o primeiro e terceiro versos representam o contrato métrico com mais exatidão -; e outras instâncias de paralelismos, como os entre "rain" e "chuva", ocasionaram as repetições e aliterações correspondentes ao original, de modo geral, o poema traduzido reproduz ambas as bases estruturais do primeiro poema, correspondendo formal e funcionalmente a ele.

\begin{tabular}{|l|l|}
\hline Quadro comparativo: "Rain, rain..." \\
\hline Rain, rain, go away & Chuva, chuva, vá embora: \\
[This is mother's washing day]; & Minha roupa está lá fora. \\
Rain, rain, pour down, & Chuva, chuva, caia agora: \\
Wash [my mother's] night-gown. & Lave a minha camisola. \\
\hline Paralelismos = negrito; Supressões = colchetes; Acréscimos = sublinhado \\
\hline
\end{tabular}


O último exemplo, conclusivo do trabalho, apresenta a nursery rhyme "Charley, Charley", primeiramente referenciada por Halliwell, em The Nursery Rhymes of England, edição revisada de 1844, como os Opie descrevem em sua coletânea, na mesma página em que se encontra o poema (OPIE; OPIE, 1952, p. 115):

\author{
Charley, Charley, \\ Stole the barley \\ Out of the baker's shop. \\ The baker came out \\ And gave him a clout, \\ Which made poor Charley hop.
}

Uma escansão simplificada de cada linha, como realizado nos exemplos anteriores, revela o seguinte:

\begin{tabular}{|c|c|c|c|c|c|c|}
\hline "Charley, Charley" & RITMO & $S$ & $A$ & ER & $\mathbf{R}$ & ALIT \\
\hline Charley, Charley, & $1-1-$ & 3 & 2 & $1-3$ & $A$ & $/+? /$ \\
\hline Stole the barley, & $1-1-$ & 3 & 2 & $1-3$ & a & \\
\hline Out of the baker's shop. & $1--1-1$ & 6 & 3 & $1-4-6$ & $b$ & \\
\hline The baker came out & $-/-1 /$ & 5 & 2 & $2-5$ & $c$ & \\
\hline And gave him a clout, & $-1--1$ & 5 & 2 & $2-5$ & $c$ & \\
\hline Which made poor Charley hop. & $-1-1-1$ & 6 & 3 & $2-4-6$ & b & \\
\hline
\end{tabular}

Diferentemente dos casos abordados, "Charley, Charley" exemplifica a métrica do common meter (cf. ballad meter: PREMINGER; BROGAN, 1993, p. 118-120). Por essa nomenclatura somente os acentos primários são contados e o primeiro e o segundo versos, bem como o quarto e o quinto são juntados para formar o contrato métrico. Tem-se, assim, que 2-2-3-2-2-3, tornam-se 4-3-4-3, característico desse tipo de estrofe; e formando um ritmo uniforme para o poema. A ocorrência do fonema $/ \mathrm{t+} " /$ no início de "Charley" e sua repetição na primeira linha demarca a única aliteração no poema. A tradução elaborada para ele, juntamente com o seu quadro estrutural, ficou assim:

Zezinho, Zezinho,

Roubou um toucinho

Do açougue do seu Mané.

Seu Mané, muito enfezado, 
No traseiro do coitado

Deu um baita pontapé.

\begin{tabular}{|l|l|l|l|c|l|l|}
\hline Tradução de "Charley, Charley" & RITMO & S & A & ER & R & ALIT \\
\hline Zezinho, Zezinho, & $-/--/-$ & 5 & 2 & $2-5$ & $\mathrm{a}$ & /z/ \\
Roubou um toucinho & $-/--/-$ & 5 & 2 & $2-5$ & $\mathrm{a}$ & \\
Do açougue do seu Mané. & $-/--/-/$ & 7 & 3 & $2-5-7$ & $\mathrm{~b}$ & \\
O açougueiro, enfezado, & $--/ /-/-$ & 7 & 2 & $4-7$ & $\mathrm{c}$ & \\
No traseiro do coitado & $--/--/-$ & 7 & 2 & $3-7$ & $\mathrm{c}$ & \\
Deu um baita pontapé. & $/-/-1-/$ & 7 & 3 & $1-3-7$ & $\mathrm{~b}$ & \\
\hline
\end{tabular}

Observa-se que tradução apresenta o mesmo tipo de contrato métrico do poema original: dois acentos no primeiro e segundo versos e, depois, dois acentos no quarto e quinto versos, que devem se juntar, resultando no esquema do original, 4-3-4-3, característico do common meter. E há uma aliteração no primeiro verso (na repetição de "Zezinho"), tal como acontece no original; e outros efeitos sonoros, ocasionados, em especial, pelo contraste entre os sons $/ z /$, sonoro, e /s/, surdo, como expresso pelos vocábulos "enfezado", "traseiro", "touçinho", "açougue", entre outros, além da própria repetição de "açougue"/"açougueiro". No entanto, o nível de correspondência formal entre os poemas é diminuído, na medida em que não apenas o tamanho dos versos foi aumentado, quanto os acentos não recaem sobre as mesmas sílabas. Desse modo, sugere-se que, nesse poema, um nível maior de correspondência se dá na esfera semântica, como apontado com mais precisão no quadro comparativo do original com a tradução:

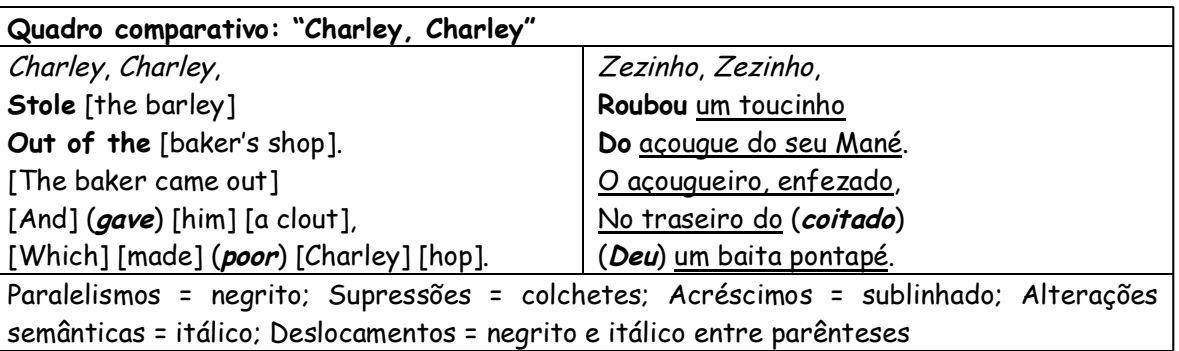

Apesar das poucas instâncias de paralelismos (em dois dos casos, por meio de deslocamentos entre os versos) e, por conseguinte, de um grande número de supressões do original e acréscimos na tradução, essas medidas são justificáveis no plano do significado, na concretização dos 
elementos de comicidade do poema. "Charley, Charley" é um poema informal, no qual, mais do que o "mau exemplo" do menino que pratica um furto, estão as noções de traquinagem da infância e das não menos infantis reações dos adultos em relação a elas. Tanto que o narrador desenfatiza a contravenção expressa por "stole" ao manifestar a sua opinião com "poor Charley" - e considerando que o próprio tapa na orelha, que o menino leva, não the causa grandes danos -, fazendo com que a história seja vista apenas pelo lado cômico. Assim, procurou-se obter, no poema traduzido, conotações do mesmo tipo, em particular, por meio da escolha dos termos "enfezado", "traseiro" e "pontapé" (afora as alterações óbvias para efeitos de rima e métrica), que pudessem promover o tom cômico e informal e sem consequências drásticas - do original. E entende-se que, dessa forma, há um nível elevado de correspondência funcional entre os dois poemas.

Como inicialmente proposto, esses "exercícios" tiveram o intuito de oferecer uma visão dos conceitos de correspondência formal e funcional, como aplicados ao processo tradutório, além de seu uso corrente na crítica de tradução poética. Concluiu-se com eles que quaisquer dos tipos de correspondência e os níveis que se possam obter de cada um na empreitada de se traduzir um poema são dependentes tanto da definição dos elementos estruturais em cada um, como do tipo de abordagem adotado para esses elementos; sendo que, desse modo, qualquer medida desses níveis será particular ao poema original e sua tradução, e podendo ser obtido somente por meio de sua justaposição. Fica, entretanto, a conclusão generalizada de que a tradução de poesia infantil impõe os mesmos tipos de desafios que a tradução de qualquer outro subgênero poético. É mesmo, como Renata Dias (2001) sugere, "uma brincadeira muito séria".

\section{Referências}

BOSSEAUX, C. "The Translation of Song". In: MALMKJ ER, K.; WINDLE, K. (eds.) The Oxford Handbook of Translation Studies. Oxford: OUP, 2011. p. 183-197.

BRITTO, P. H. "Avaliação de Tradução de Poesia". Palestra apresentada na Faculdade de Filosofia, Letras e Ciências Humanas da Universidade de São Paulo, no dia 12 de maio de 2011, como parte do "Ciclo de Palestras sobre Teoria da Tradução", organizado pelo Centro Interdepartamental de Tradução e Terminologia (CITRAT/FFLCH/USP). 
CARPENTER, H.; PRICHARD, M. The Oxford Companion to Children's Literature. Oxford: OUP, 1984.

CARROLL, L. The Annotated Alice, comentários de Martin Gardner, ilustrações de John Tenniel. Harmondsworth: Penguin, 1965.

Alice no País das Maravilhas, tradução de Ana Maria Machado, ilustrações de Jô de Oliveira. São Paulo: Ática, 1997.

DAVID, B. R. Mark Twain and his Illustrators, Vol. I (1869-1875). Albany: Whitston Publishing Company, Inc., 1986.

DIAS, Renata de Sousa. "Traduzir para a Criança: uma Brincadeira Muito Séria". Dissertação de Mestrado, tomos I e II. São Paulo, FFLCH/USP, 2001.

HANCOCK, C. R. "The Singing Tradition of Nursery Rhymes". In: OPIE, I; OPIE, P. (eds.) The Oxford Dictionary of Nursery Rhymes. Oxford: OUP, 1997.

JONES, F. R. "The Translation of Poetry". In: MALMKJ AER, K.; WINDLE, K. (eds.) The Oxford Handbook of Translation Studies. Oxford: OUP, 2011. p. 169-182.

OPIE, I. "Playground Rhymes and the Oral Tradition". In: HUNT, P. (ed.) International Companion Encyclopedia of Children's Literature. London/ New York: Routledge, 1996. pp. 177-189.

OPIE, I; OPIE, P. (eds.) The Oxford Dictionary of Nursery Rhymes. Oxford: OUP, 1952. Oxford: OUP, new edition, 1997. A Family Book of Nursery Rhymes. Oxford: OUP, 1964.

PREMINGER, A.; BROGAN, T. V. F. The New Princeton Encyclopedia of Poetry and Poetics. Princeton: Princeton University Press, 1993.

ROSSETTI, C. Sing-Song: A Nursery Rhyme Book. London: Macmillan and Co. Ltd., 1922. 